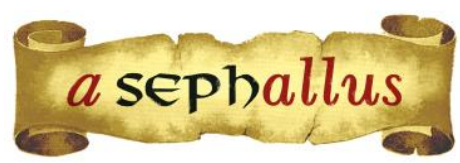

Revista aSEPHallus de Orientação Lacaniana

Núcleo Sephora de Pesquisa sobre o Moderno e o Contemporâneo

ISSN $1809-709 \mathrm{X}$

\title{
A realidade não contada do enfrentamento à pandemia - relatos de uma médica na linha de frente contra o novo coronavírus
}

\author{
Mariana Gonçalves Musauer \\ Orcid: https://orcid.org/0000-0002-7592-2582 \\ Graduada em Medicina pela Universidade Federal do Rio de Janeiro/UFRJ (Rio de Janeiro, Brasil) \\ Professora da Pós-Graduação em Clínica da Dor PUC-RJ e Américas Medical City (Rio de Janeiro, Brasil) \\ Residência em Anestesiologia no Instituto Nacional do Câncer/INC (Rio de Janeiro, Brasil) \\ Título de Especialista em Anestesiologia Associação Médica Brasileira (Brasil) \\ Área de atuação em Medicina da Dor Associação Médica Brasileira (Brasil) \\ Certificada pelo World Institute of Pain/WIP (North Carolina, EUA) \\ Mestranda em Sistema Musculo-Esquelético no Instituto Nacional de Traumatologia e Ortopedia \\ e-mail: marianamusauer@gmail.com
}

\begin{abstract}
Resumo: No início da pandemia do novo coronavírus fomos tomados de incertezas que nos atrapalharam a usar o bom senso, turbinadas pelas mídias sensacionalistas que anunciavam a catástrofe sem precedentes. 0 contexto criado pela mídia fez com que a maioria dos médicos se sentisse impotente diante da ameaça da "nova" doença. A desconstrução do saber médico se deu diante das afirmações contundentes de epidemiologistas renomados lendo os números pelos números. O bom senso não é construído em estudos randomizados controlados, é construído com experiências. Em nossa prática, o cuidado é cem por cento das vezes individualizado.
\end{abstract}

Palavras-chave: Pandemia; Coronavírus; Estudos Randomizados, Prática.

La réalité indicible de la gestion de la pandémie - rapports d'un médicin en première lingne contre le nouveau coronavirus: Au début de la nouvelle pandémie de virus corona, nous avons été submergés par des incertitudes qui nous ont empêchés d'utiliser le bon sens, alimentés par les médias sensationnalistes qui ont annoncé une catastrophe sans précédent. Le contexte créé par les médias a incité la plupart des médecins à se sentir impuissants face à la menace de la «nouvelle» maladie. La déconstruction des connaissances médicales a eu lieu face aux déclarations énergiques d'épidémiologistes renommés lisant les chiffres par les chiffres. Le bon sens ne se fonde pas sur des études contrôlées randomisées, mais sur l'expérience. Dans notre pratique, les soins sont cent pour cent du temps individualisés.

Mots-clés: Pandémie, Coronavirus, Études Randomisées, Pratique.

The untold reality of coping with the pandemic - reports from a doctor on the front lines against the new coronavirus: At the beginning of the new corona virus pandemic, we were overcome by uncertainties that hindered us to use common sense, fueled by the sensationalist media that announced the unprecedented catastrophe. The context created by the media made most doctors feel helpless in the face of the threat of the "new" disease. The deconstruction of medical knowledge took place in the face of the forceful statements of renowned epidemiologists reading the numbers. Common sense is not built on randomized controlled studies, it is built on experience. In our practice, care is one hundred percent of the time individualized.

Keywords: Pandemics, Coronavirus, Randomized Studies, Practice.

Revista aSEPHallus de Orientação Lacaniana. Rio de Janeiro, 15(29), 140-146, nov. 2019 a abr. 2020.

A realidade não contada do enfrentamento à pandemia - relatos de uma médica na linha de frente contra o novo coronavírus

Mariana Gonçalvez Masauer 


\title{
A realidade não contada do enfrentamento à pandemia - relatos de uma médica na linha de frente contra o novo coronavírus
}

\author{
Mariana Gonçalvez Musauer
}

Esta é uma situação única e inédita para nossa geração, e algumas anteriores: o enfrentamento a uma pandemia mundial. As fases do enfrentamento foram evoluindo com o tempo - da descrença na gravidade da doença às incertezas sobre sua evolução, para o pânico generalizado pelo estado de calamidade pública e mortes em ascensão, passando por entraves políticos e filosóficos, que misturados à ciência, tentavam dar conta de tratar uma nova doença, nem tão desconhecida assim (Hawryluck et al., 2005). Atualmente, passamos por uma certa acomodação com a probabilidade de convivência com a doença por um longo período de tempo e consequente tentativa de retorno à normalidade. Um inimigo conhecido.

Dentro desse contexto, os profissionais da saúde, apesar da suposta posição de vantagem pelo conhecimento técnico inerente, padeceram das mesmas angústias. Posso afirmar como médica que sou, trabalhando tanto na medicina privada quanto na medicina pública do Rio de Janeiro. Em março, os primeiros pacientes começavam a chegar nas emergências com sintomas respiratórios que evoluíam rapidamente em gravidade, assustando a todos. Os colegas trocavam mensagens incessantes sobre o que fazer, o que tomar, e teorias sobre a infecção pelo novo coronavírus, muitas vezes distribuindo fake news angustiantes. O medo e a ansiedade pareciam colocar os profissionais de saúde em um lugar comum - junto à população leiga.

Um dos aspectos mais intrigantes de todo esse processo catastrófico pelo qual passamos foi a percepção da perda do que chamarei de bom senso médico. O bom senso subliminar. Aquele adquirido nas centenas de vezes que atendemos casos semelhantes de uma patologia desde a faculdade, que discutimos com professores, colegas médicos e residentes, em passagens de plantão ou trocas de opinião. Aquele que usamos para deixar nossa impressão de como o paciente está evoluindo, e decidirmos cada próxima conduta para um determinado caso - e esse bom senso não é construído em estudos randomizados controlados, é construído com experiências. Em nossa prática, o cuidado é cem por cento das vezes individualizado. Mesmo que não nos demos conta disso.

Fomos tomados de incertezas que nos atrapalharam a usar o bom senso, turbinadas pelas mídias sensacionalistas que anunciavam a catástrofe sem precedentes. O contexto criado pela mídia fez com que a maioria dos médicos se sentisse impotente diante da ameaça da "nova" doença. A desconstrução do saber médico se deu diante das afirmações contundentes de epidemiologistas renomados lendo os números pelos números. Por que o paciente apresentava uma insuficiência respiratória de evolução tão rápida? Por que alguns apresentavam uma reação inflamatória tão grave? Quem seriam esses? Como tratar?

Revista aSEPHallus de Orientação Lacaniana. Rio de Janeiro, 15(29), 140-146, nov. 2019 a abr. 2020.

A realidade não contada do enfrentamento à pandemia - relatos de uma médica na linha de frente contra o novo coronavírus 
É evidente que se faz necessário desenvolver protocolos ou guidelines quando se fala de saúde pública e das grandes especialidades da medicina de uma maneira geral. Esses protocolos são desenhados para guiar e uniformizar condutas, através do estudo de bases de dados e publicações sobre uma determinada patologia, analisando risco, custos e benefícios das mais variadas intervenções propostas, indicando desde quais exames pedir até qual medicamento administrar. Contudo, deve-se salientar que são fruto de extenso trabalho de pesquisadores, ou seja, não nascem da noite para o dia. Além disso, estão em constante atualização, pré-requisito da ciência médica desde os seus primórdios.

Entretanto, com o aparecimento de uma "nova" doença (existem várias publicações prévias sobre infecções por coronavírus provenientes de animais e similares) com alto grau de transmissibilidade, não há tempo para aguardar o próximo guideline. Os pacientes estavam chegando. O que fazer? Afinal, não é uma gripezinha, mas é uma virose. $E$ desde a faculdade somos ensinados que viroses podem se apresentar com os mais variados sintomas, a depender da condição imunológica do paciente, e mesmo nos dias atuais, poucas possuem tratamento específico. A prática médica foi questionada e atropelada por um jogo político travestido de ciência. Quase todos os protocolos da Terapia Intensiva já previam, por exemplo, o uso de corticoesteroides para esse tipo de acometimento inflamatório pulmonar característico da doença, mas foi preciso haver uma publicação em jornal científico renomado para validar seu uso. 0 bom senso foi posto à prova.

\section{A Chegada no CTI}

Há 8 anos não pisava em um Centro de Terapia Intensiva (CTI), a não ser para conduzir pacientes operados e por mim anestesiados ao período de recuperação pós-operatória. No entanto, em meados de abril fui convocada ao dever profissional, de encontro ao nosso Juramento de Hipócrates - trabalhar como plantonista do CTI COVID-19 no Hospital Universitário público em que exerço a função de médica especialista em Dor Crônica. Sem hesitar, me apresentei no dia seguinte à convocação para o primeiro plantão. As angústias sobre a própria saúde e a probabilidade de contaminação de familiares foram reais, além da exaustão pelos plantões noturnos que se seguiriam, mas a medicina acabou se tornando, pelo menos pra mim, uma missão prioritária. Não houve dúvidas de que eu deveria contribuir com meu trabalho.

Para minha surpresa, o primeiro plantão foi um divisor de águas, e as angústias diminuíram quando eu me deparei com o primeiro paciente COVID - um paciente exatamente igual à tantos outros que atendi nos meus anos atuando em CTI ou que ouvi falar nos meus 11 anos de exercício da profissão. Um paciente grave. Tubo, acessos, sondas, bombas, ventilação mecânica, hemodiálise, entre outros. Mesmo considerando algumas características específicas da doença, como o risco aumentado de eventos trombóticos, a hipoxemia (falta de oxigênio no

Revista aSEPHallus de Orientação Lacaniana. Rio de Janeiro, 15(29), 140-146, nov. 2019 a abr. 2020.

A realidade não contada do enfrentamento à pandemia - relatos de uma médica na linha de frente contra o novo 
sangue) abrupta e sem prenúncio que alguns pacientes apresentavam ou ainda o acometimento pulmonar grave e demorado, característico da fase inflamatória, nada parecia ser inédito. A cronologia da doença, no início pouco conhecida, confundia em algumas ocasiões, mas rapidamente aprendemos o que esperar e que o tratamento principal nos casos graves é o de suporte. Tratamento que precisa de recursos humanos, muito mais do que ventiladores, auxiliado pelos protocolos prévios extensamente utilizados na terapia intensiva. O bicho deixou de ter sete cabeças.

Sabemos que a mídia expôs somente os números absolutos da desgraça, que soavam muito piores que as estatísticas percentuais e comparativas. Foi enfatizado que nenhuma medicação daria conta de tratar esse vírus ameaçador. A ciência virou palco de briga política, como vivenciado com a cloroquina, medicação utilizada há tempos e bastante conhecida dos médicos, que foi demonizada. Mas na prática assistencial, sabemos, e não foi novidade: utilizamos os guidelines de tratamento de síndrome da angústia respiratória grave, que dá o nome à doença SARS, seja causada pelo novo coronavírus, ou por qualquer outro vírus ou patógeno já conhecidos. Corticoides, aminas, ventilação mecânica, antibióticos, anticoagulantes, com algumas pequenas adaptações - velhos conhecidos. Além disso, a probabilidade de evolução para doença grave pode estar relacionada à carga viral (Chaudhry; McBride et al., 2020), e as medidas para diminuição desta, seja na precaução da exposição ou na utilização precoce de medicações antivirais, pode ser bastante benéfica, e deve sem dúvidas ser considerada. Os médicos, enfim, começaram a recuperar o "bom senso", mas poucos se posicionaram publicamente para trazer informação de qualidade para todos.

\section{A realidade}

A primeira realidade que posso compartilhar é a de um hospital público universitário que atuou no combate à COVID-19. Foi montada uma unidade temporária em local adaptado, que apesar disso contou com distribuição de equipamentos de proteção individual a todos os funcionários, sem desabastecimento, além de respiradores e bombas de infusão para todos os leitos disponíveis e equipe multidisciplinar capacitada que envolvia médicos especialistas, enfermeiros, fisioterapeutas, técnicos de enfermagem, fonoaudiólogas, psicólogas, entre outros. Foi inclusive ofertado atendimento psicológico aos familiares de pacientes internados. Ligávamos pessoalmente, nós médicos, todos os dias para dar notícias aos familiares. Alguns recursos de alta complexidade não estavam disponíveis, como a terapia de oxigenação por membrana extracorpórea (ECMO), utilizada em casos de gravíssimo acometimento pulmonar. Porém, poucos são disponíveis mesmo na rede privada de saúde, e seu uso reservado à casos isolados e muito graves. Apesar das notícias de roubos nas licitações e falta de insumos, nada faltou em nosso Hospital.

Revista aSEPHallus de Orientação Lacaniana. Rio de Janeiro, 15(29), 140-146, nov. 2019 a abr. 2020.

A realidade não contada do enfrentamento à pandemia - relatos de uma médica na linha de frente contra o novo coronavírus 
A segunda realidade é a observação de que, como em toda virose, existe uma grande dificuldade em descobrir medicamentos específicos para tratamento. É inerente ao mecanismo de infecção e à fisiologia viral. O quadro clínico apresentado é dependente da resposta do sistema imunológico do infectado. Se analisarmos o tratamento de outras tantas viroses que conhecemos há anos, veremos medicações antivirais com ação limitada às fases iniciais, ou mesmo vírus que até hoje são tratados com dipirona e outros sintomáticos - como o vírus da dengue. Não há surpresa em não haver medicação específica para o tratamento do novo coronavírus. Talvez não haja. A população precisa de informação de qualidade - de que não há grande expectativa de que uma única medicação possa curar a doença, que as associações medicamentosas quando prescritas no tempo certo pelo médico (grande problema do nosso SUS - acesso a avaliação médica em tempo adequado) podem sim mudar o curso da doença e que, se mesmo assim houver evolução para a forma grave, o tratamento será o de suporte, em terapia intensiva. Isso também não é novidade, mas ninguém comenta. Por que será? Interesses políticos para garantir projeção e reeleição? Interesses da indústria farmacêutica em propagandear e vender suas caras medicações? Ou interesse pela manutenção da venda crescente de insumos hospitalares como respiradores mecânicos e equipamentos de proteção individual?

A terceira e última realidade ou verdade que gostaria de considerar é a de que o grande problema dessa doença foi acometer muitas pessoas em curto espaço de tempo. Sua letalidade não é relativamente alta, gira em torno de 3\% (considerado baixo) no Brasil e no resto do mundo, com alterações entre países e alguns grupos etários e étnicos. Como comparação, a infeç̧ão pelo vírus Influenza que causou a gripe aviária pode apresentar taxa de letalidade de até $60 \%$ (Wang, Parides \& Palese, 2012). Mas o pouco de muito, continua muito. E não entraremos no mérito de que cada vida importa porque nunca houve esse tipo de questionamento. Lutamos por cada paciente.

Assim, o sistema de saúde chegou ao limite, realidade já previamente conhecida pelo SUS. E assim são apresentados os números catastróficos, que se contextualizados, não representam o apocalipse antes anunciado. Agora, com o início do arrefecimento da pandemia, faz-se necessário entender que conviveremos algum tempo com esta doença, e que ela não se extinguirá até que grande parte da população adquira imunidade, seja pelo contato com o vírus selvagem ou através de vacina, que normalmente tem um longo processo de produção. Precisamos retornar à normalidade com os devidos cuidados preconizados no convívio social - distanciamento e uso de máscaras.

\section{Considerações finais}

A COVID-19 não é uma doença alienígena, e talvez pareça mais complexa do que as outras porque nunca estudamos tanto e com tanta intensidade sobre uma doença viral. Hoje,

Revista aSEPHallus de Orientação Lacaniana. Rio de Janeiro, 15(29), 140-146, nov. 2019 a abr. 2020.

A realidade não contada do enfrentamento à pandemia - relatos de uma médica na linha de frente contra o novo coronavírus 
sabemos tratar com muito mais propriedade e menos alarme um paciente infectado pelo novo coronavírus do que no início da pandemia. Em minha observação atual, os novos casos, em sua maioria, têm se apresentado com menos gravidade. Eu mesma acabei de descobrir que desenvolvi anticorpos de longa duração (IgG) contra o Sars-cov-2 sem nunca ter desenvolvido quaisquer sintomas.

Infelizmente, a isenção esperada na construção do conhecimento científico foi severamente afetada ou desmascarada pela pandemia. O que se viu foi uma enxurrada de publicações de má qualidade e tendenciosas, e me sinto no dever como médica e estudante de mestrado de continuar propagando e produzindo conhecimento científico relevante e isento de segundas intenções.

Em resumo: eventualmente entraremos em contato com o vírus, vacinalmente ou não, e só assim as novas contaminações se tornarão insignificantes; provavelmente será menos traumático ficar doente agora do que no início da pandemia, quando não sabíamos ao certo o que fazer e havia uma ameaça constante de falta de leitos nos hospitais e, finalmente, devemos acabar com a politização da pandemia e cuidar da saúde da ciência para fazermos considerações realísticas sobre o que nos aguarda e vivermos o novo normal - o futuro.

\section{Referências bibliográficas}

Chaudhry, F.; McBride, R. et al. (2020). SARS-CoV-2 viral load predicts COVID-19 mortality. Lancet Respir Med. 2020;8(9):e70. doi:10.1016/S2213-2600(20)30354-4. Recuperado em: 15/07/2020. Disponível em:

<https://www.thelancet.com/journals/lanres/article/PIIS2213-2600(20)30354-4/fulltext>

Hawryluck, L.; Lapinsky S.E.; Pujadas, E.; Stewart, T.E. (2005). Clinical review: SARS - lessons in disaster management. Crit Care;9(4):384-389. doi: 10.1186/cc3041. Recuperado em: $15 / 07 / 2020$.

em: https://www.researchgate.net/publication/7624614_Clinical_review_SARS__Lessons_in_disaster_management

Wang, T.T.; Parides, M.K.; Palese, P. (2012). Seroevidence for H5N1 influenza infections in humans: meta-analysis. Science. 2012;335(6075):1463. doi:10.1126/science.1218888. Recuperado em: 15/07/2020. Disponível em: <https://science.sciencemag.org/content/early/2012/02/22/science.1218888/tab-eletters?versioned=true>

Revista aSEPHallus de Orientação Lacaniana. Rio de Janeiro, 15(29), 140-146, nov. 2019 a abr. 2020.

A realidade não contada do enfrentamento à pandemia - relatos de uma médica na linha de frente contra o novo coronavírus 
Citação/Citation: Gonçalvez Masauer, M. (nov. 2019 a abr. 2020). A realidade não contada do enfrentamento à pandemia - relatos de uma médica na linha de frente contra o novo coronavírus. Revista aSEPHallus de Orientação Lacaniana, 15(29), 140-146. Disponível em www.isepol.com/asephallus. Doi: 10.17852/1809-709x.2020v15n29p140-146

Editor do artigo: Tania Coelho dos Santos.

Recebido/Received: 10/03/2019 / 03/10/2019.

Aceito/Accepted: 10/20/2019 / 20/10/2019.

Copyright: @ 2019 Associação Núcleo Sephora de Pesquisa sobre o moderno e o contemporâneo. Este é um artigo de livre acesso, que permite uso irrestrito, distribuição e reprodução em qualquer meio, desde que $o$ autor e a fonte sejam citados/This is an open-access article, which permites unrestricted use, distribution, and reproduction in any medium, provided the author and source are credited. 